Volume 8, No.3, May - June 2019

International Journal of Advanced Trends in Computer Science and Engineering

Available Online at http://www.warse.org/IJATCSE/static/pdf/file/ijatcse72832019.pdf

https://doi.org/10.30534/ijatcse/2019/72832019

\title{
Automated Hazardous Gas Detecting Robot using Wireless Sensor Networks with GSM-SMS Alert and Fire Control System for Households
}

\author{
Edward B. Panganiban ${ }^{1}$ \\ ${ }^{1}$ College of Computing Studies, Information and Communication Technology, Isabela State University \\ Echague, Isabela, Philippines, ebpanganiban@isu.edu.ph
}

\begin{abstract}
Over the past decades, fire cannot be prevented in our homes and society. Hence, the author came up with an idea to create a robot that will serve as first responder to fire and hazardous chemicals. Problems were identified and objectives were formulated as guides in the establishment "Automated Hazardous Gas Detecting Robot using Wireless Sensor Networks with GSM-SMS Alert and Fire Control System for households". This robot is designed having two wheeled drive navigation to easily move and detect hazardous substances and fires. It is equipped with gas sensor to monitor if there is a gas leakage in a room and is programmed to automatically send messages to the registered number using GSM Module. It was installed to be able to send Short Messaging Service (SMS). This paper is about a microcontroller based project, with microelectronics devices, namely, Flame Sensor (KY-026), GSM Module (SIM 900A), gas sensor (MQ-2), L293D Motor Shield, a 12V DC motor and 12V DC Water Pump, Arduino UNO, a light emitting diode (LED) and a buzzer. These were carefully programmed and patiently tested to ensure its working conditions. Through well-planned design, data gathering and testing its reliability, the author came up with an automated detection system in a robotic application with features like SMS notification, an alarm system and extinguishing fire. The author concluded that this project is reliable and can help the homeowners secure their home from the blazing disaster brought by fire and hazardous gases.
\end{abstract}

Key words: gas hazards, gsm-sms, microcontroller, robot, sensors

\section{INTRODUCTION}

Fire protection reduces the impact of an uncontrolled fire, save lives and property. Over the years, technology is fast paced and different security devices were innovated. Robotics is one of the quickest rising engineering researches of today. Detection and locating hazardous gases is a public interest in preventing harms to humans, nature and assets [1]-[2]. Leak detection technologies and development is needed to address such problems. Robots are intended to avoid human factor from difficult job or unsafe work and for remote location applications. Robotic solutions are available in the form of In-Pipe Inspection Robots and Tank Inspection Robots [3]. It can detect leaks in a pipe system through the use of electronic sensors. It has the ability in detecting single or multiple leaks in pipeline [4]-[5]. In fact, there are robotic technologies widely used in offshore oil and gas industry nowadays [6]. In this paper, gas detection is one of the important roles in fire prevention for households. Gas detection is made possible through several approaches like gas leakage localization applied through the help of a mobile carrier or wheeled robot [7]. It can also detect gas through the application of passive IR-thermography or can be IR-optical sensor to allow remote leak detection based from the gas pressure [8]-[9]. Chemicals like gas can also be sensed through a mobile robot equipped with chemical sensors that can follow chemical trails left on the ground and find their roots [10]. Through the emergence of new technologies, remote gas sensing is made possible through mobile robots [11]-[12].

The main device used in this paper is the integration of a microcontroller. Microcontroller can be programmed to detect gas leakage. This can be applied to detect LPG gas with a mobile communication for security measures [13]. This automated hazardous gas detecting robot using wireless sensor networks with gsm-sms alert and fire control system for households is designed and built with an embedded system that aimed as an aide in fire protection. With this kind of device, human and property can be saved in a much higher percentage with comparatively minimal destruction caused by the fire.

This paper implemented a wireless sensor networks (WSN) because it involves multiple sensors and its capability to process and communicate with other electronic devices [14]. This paper also adopted WSNs due to its multi-sensory capability to improve its intelligence system and robotics applications [15]-[17]. Furthermore, robotics [18] is one of many applications of multiple sensors [19] and is being used for automation [20].

Aside from the WSN feature of this paper, it also involves GSM module for SMS notification. This module sends sms to the mobile phone that will provide a warning that there might be a fire detected by the robot. This GSM module is built with Dual Band GSM/GPRS engine SIM900A with 900/1800 $\mathrm{MHz}$ frequency. It is suitable for SMS, voice as well as for 
data transfer application [21]. This is integrated to secure and monitor home as what previous study established [22].

Through this, the author come up with a novel robotics application intended for fire protection that can detect flame, an object, smoke and gas with an alarm system composed of LED and buzzer, a GSM module for SMS notification and a water pump to extinguish the fire. The combination of these functions makes the author challenged to establish a research that can help our society.

\section{MATERIALS AND METHODS}

\subsection{General System Design}

The system's design involved wireless sensor networks (WSN) using multiple sensor nodes. It has two arduino uno microcontrollers. Each microcontroller has different sensors attached to it. The arduino uno is a microcontroller board that is based on the ATmega328 which comprises of 14 digital input/output pins and 6 analog inputs [23]. It is a powerful device that you can code, erase and recode at any given time [24]. This is reliable for several robotics applications [25].

The general concept of this paper is illustrated through figure 1 and 2. These figures are the system architectures that explain the functionalities of the automated hazardous gas detecting robot. Figure 1 is the diagram of the navigation function of the automated hazardous gas detecting robot. When the MQ-2 Smoke Sensor detects smoke in the air it will activate HC-SR04 Ultrasonic Sensor to be move closer to the smoke. The MQ-2 gas sensor is a highly sensitive to substances Tin Oxide ( $\mathrm{SnO} 2)$, which has low conductivity in clean air. When flammable gas is detected, the sensor will have higher conductivity and the concentration of the gas will also increase [14],[26]. The HC-SR04 ultrasonic sensor emits high-frequency sound wave $(40 \mathrm{kHz})$ through one of its piezoelectric transducers and detects the returning pulses (echo) in the air through another transducer and converts it to proportional voltage variation [27].

However, when the ultrasonic sensor detects an obstacle it sends data to the Arduino UNO microcontroller to inform the L293D motor shield be responsible for the desired rotation of DC motors to move to the best location to move nearer the smoke source. If there is a fire from the smoke source, the flame detector will be activated and the data will be processed in the Arduino microcontroller. It will then activate the alarm system which composed of the LED and buzzer. The SIM900 GSM Module will then send notification to the owner. After that, the L293D motor shield allows the DC motor to move in the direction of the fire detected and the fire extinguisher will activate.

Figure 2 illustrates the detection of gas using the MQ-2 gas detector. When it detects gas the Arduino UNO microcontroller analyses the data allowing the alarm system which consists of an LED and a buzzer to be activated and the Sim800 GSM module to send SMS notification.

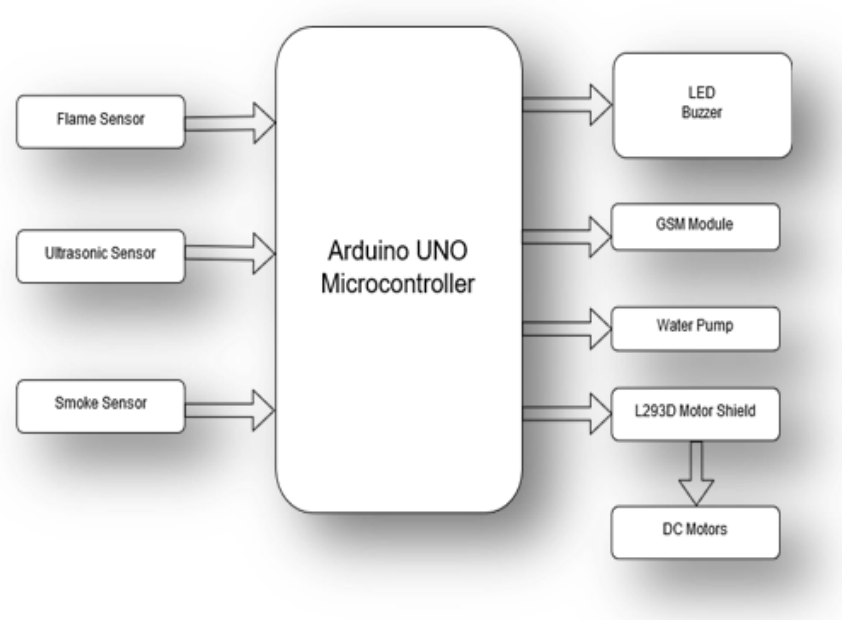

Figure 1: System Architecture of the automated hazardous gas detecting robot (navigation function)

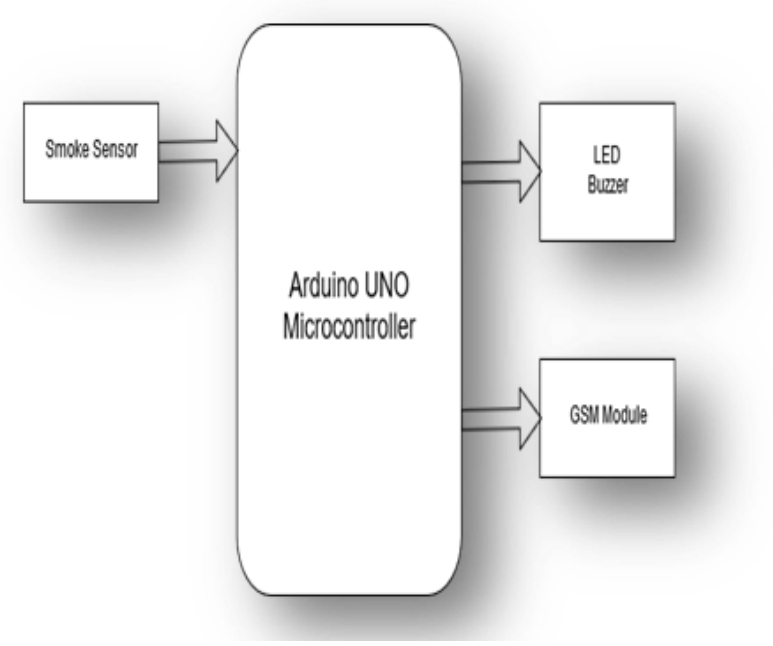

Figure 2: System Architecture of the automated hazardous gas detecting robot (detection function)

\subsection{System Flowchart}

Figure 3 illustrates the detailed task of the robot. It explains the step-by-step procedure on how the system works. It is equipped with sensors capable of detecting 4 major inputs which are smoke, obstacle, flame and gas. The smoke sensor that triggers the navigation system of the robot. The ultrasonic sensor detects an obstacle allowing the robot to move back and avoid collision. Flame sensor identifies if there is a fire. Finally, the gas sensor detects gas leakage. When the robot detects a fire or a gas leakage, it will activate the alarm system which composed of an LED and a buzzer then it will send a Short Messaging Service (SMS) to notify the owner. 


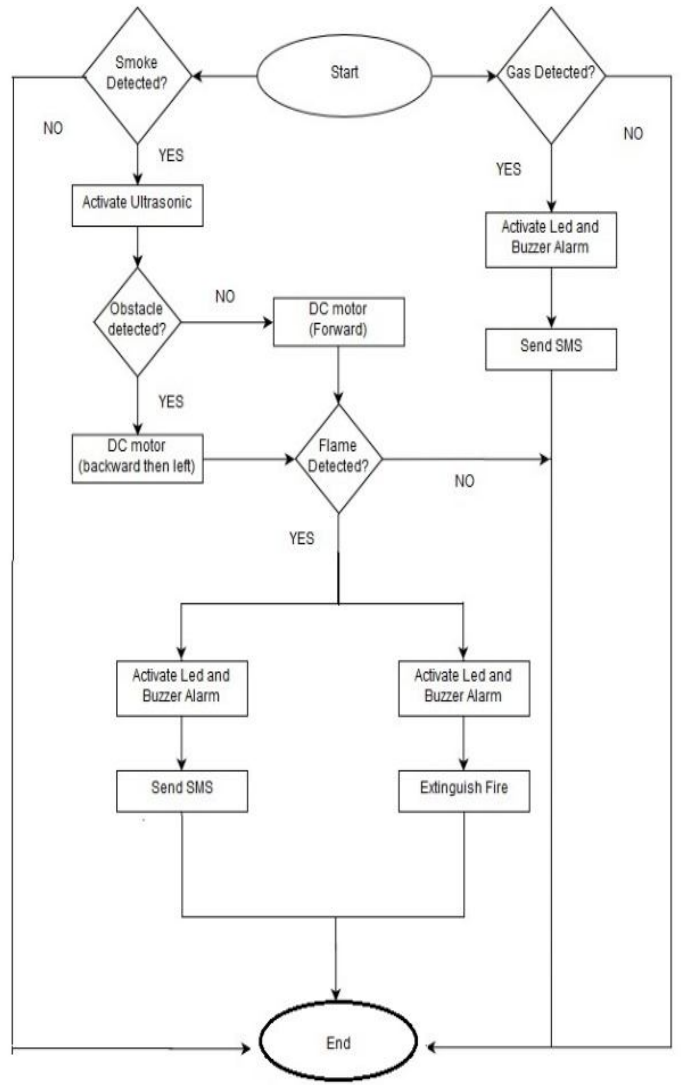

Figure 3: System Flowchart

\subsection{Wiring Diagram}

The wiring diagram of its circuitry is shown in figure 4 . It illustrates as a guide in connecting each of the components used for the project. The main device used is the Arduino Uno microcontroller that serves as the brain of all the components connected. The flame sensor, a smoke sensor, ultrasonic sensor and gas sensor serves as the input sensors which triggers different operations and activate other devices like GSM module, which will send notification to the owner, LED and a buzzer which serves as the alarm and the water pump which can extinguish the fire detected.

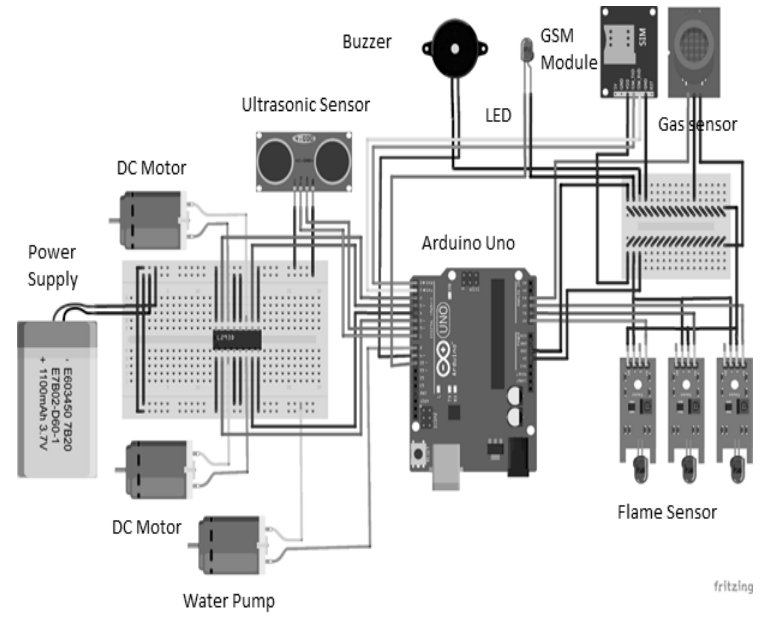

Figure 4: Wiring Diagram

\section{RESULTS AND DISCUSSION}

One important phase in establishing this paper is the testing the functionalities of the prototype or the robot itself. It was put into several tests to come up with a desirable output. Tests includes unit testing, acceptance testing and integration testing. Unit testing was established to assess all the components used and make sure that all are functioning. Acceptance and integration testing guaranteed that all runs according to its objectives. Detailed tests in the given next tables which showed the reliability of the robot.

\subsection{Testing Results}

Table 1. Smoke and Flame detection test (a)

\begin{tabular}{|l|l|l|l|l|l|}
\hline Trial & $\mathbf{1}$ & $\mathbf{2}$ & $\mathbf{3}$ & $\mathbf{4}$ & $\mathbf{5}$ \\
\hline $\begin{array}{l}\text { Smoke } \\
\text { presence }\end{array}$ & YES & YES & YES & YES & NO \\
\hline $\begin{array}{l}\text { Smoke } \\
\text { detection }\end{array}$ & YES & YES & YES & YES & NO \\
\hline $\begin{array}{l}\text { Ultrasonic } \\
\text { activation }\end{array}$ & YES & YES & YES & YES & NO \\
\hline $\begin{array}{l}\text { Obstacle } \\
\text { presence }\end{array}$ & NO & YES & NO & NO & NO \\
\hline $\begin{array}{l}\text { DC motor } \\
\text { movement }\end{array}$ & Forward & $\begin{array}{l}\text { Backward } \\
\text { then left }\end{array}$ & Forward & Forward & $\begin{array}{l}\text { Move } \\
\text { ment }\end{array}$ \\
\hline $\begin{array}{l}\text { Flame } \\
\text { presence }\end{array}$ & YES & YES & YES & YES & NO \\
\hline $\begin{array}{l}\text { Alarm } \\
\text { activation } \\
\text { (LED and } \\
\text { Buzzer) }\end{array}$ & YES & YES & YES & YES & NO \\
\hline SMS & YES & YES & YES & YES & NO \\
\hline Extinguish & YES & YES & YES & YES & NO \\
\hline
\end{tabular}


Edward B. Panganiban , International Journal of Advanced Trends in Computer Science and Engineering, 8(3), May - June 2019, 804 - 809

Table 2. Smoke and Flame detection test (b)

\begin{tabular}{|l|l|l|l|l|l|}
\hline Trial & $\mathbf{6}$ & $\mathbf{7}$ & $\mathbf{8}$ & $\mathbf{9}$ & $\mathbf{1 0}$ \\
\hline $\begin{array}{l}\text { Smoke } \\
\text { presence }\end{array}$ & YES & YES & YES & NO & YES \\
\hline $\begin{array}{l}\text { Smoke } \\
\text { detection }\end{array}$ & YES & YES & YES & NO & YES \\
\hline $\begin{array}{l}\text { Ultrasonic } \\
\text { activation }\end{array}$ & YES & YES & YES & NO & YES \\
\hline $\begin{array}{l}\text { Obstacle } \\
\text { presence }\end{array}$ & YES & YES & NO & NO & NO \\
\hline $\begin{array}{l}\text { DC motor } \\
\text { movement }\end{array}$ & $\begin{array}{l}\text { Backward } \\
\text { then left }\end{array}$ & $\begin{array}{l}\text { Backward } \\
\text { then left }\end{array}$ & Forward & $\begin{array}{l}\text { Move } \\
\text { ment }\end{array}$ & $\begin{array}{l}\text { Forw } \\
\text { ard }\end{array}$ \\
\hline $\begin{array}{l}\text { Flame } \\
\text { presence }\end{array}$ & YES & NO & YES & NO & YES \\
\hline $\begin{array}{l}\text { Alarm } \\
\text { activation } \\
\text { (LED and } \\
\text { Buzzer) }\end{array}$ & YES & NO & YES & NO & YES \\
\hline SMS & YES & NO & YES & NO & YES \\
\hline Extinguish & YES & NO & YES & NO & YES \\
\hline
\end{tabular}

Table 1 and 2 are details of the smoke and flame detection test. It shows the responses of smoke, ultrasonic and flame sensors. The number of trials given in the table are just samples extracted from several trials made by the author. There are 5 trials with both smoke and flame presence, 3 trials with smoke presence only and 2 trials with none of these were tested. Three trials were tested with obstacles. If an obstacle is detected, the robot will move backward then turn left then move forward until the source is located. Based from the given table, is there is a presence of flame, then it will activate the alarm system made up of a buzzer and an LED and it will also send SMS to the person informing that there is a fire going on.

Table 3. Gas Detection Test

\begin{tabular}{|l|l|l|l|l|}
\hline Trial & $\begin{array}{l}\text { Gas } \\
\text { presence }\end{array}$ & $\begin{array}{l}\text { Gas } \\
\text { detection }\end{array}$ & $\begin{array}{l}\text { Alarm } \\
\text { activation (LED } \\
\text { and Buzzer) }\end{array}$ & SMS \\
\hline 1 & YES & YES & YES & YES \\
\hline 2 & YES & YES & YES & YES \\
\hline 3 & YES & YES & YES & YES \\
\hline 4 & YES & YES & YES & YES \\
\hline 5 & YES & YES & YES & YES \\
\hline 6 & YES & YES & YES & YES \\
\hline 7 & YES & YES & YES & YES \\
\hline 8 & YES & YES & YES & YES \\
\hline 9 & NO & NO & NO & NO \\
\hline 10 & NO & NO & NO & NO \\
\hline
\end{tabular}

Gas detection test was also established to determine the performance of the robot. Table 3 shows the result of gas detection test made by the author. The number of trials given in the table are just samples extracted from several trials made by the author. There are 8 trials with gas presence and the other 2 trials without gas presence. In here, it shows that when there is a presence of gas leakage, the alarm system will be activated and SMS will be sent to the person concerned. Hence, the table has proven the good performance of the robot according to its desired function.

\subsection{Design Output}

Figure $5 \mathrm{a}$ and $5 \mathrm{~b}$ show the final design output of the automated hazardous gas detecting robot. It also shows the labeled location of every component integrated inside. The robot will work if it is turned on using the switch found at the rear side of the robot. Every labeled component has its own functions. Its main body is made up of customized aluminum for protection of electronic components. Inside the casing are the devices used such as flame sensor, gas sensor, smoke sensor, GSM Module, LED, a buzzer, water pump, L293D motor shield, battery indicator, ultrasonic sensor, and a bottle as a storage for fire extinguisher material.

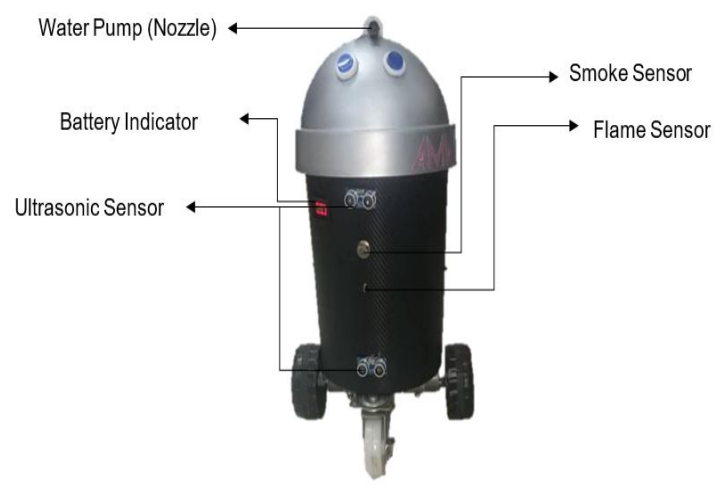

Figure 5a. The final design output of the automated hazardous gas detecting robot (front view)

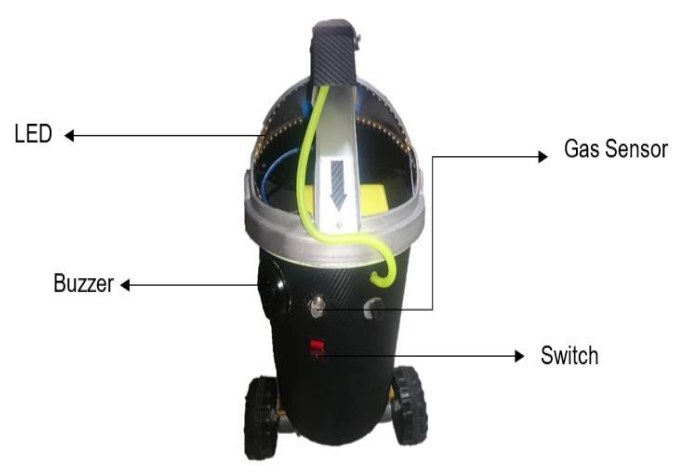

Figure 5b. The final design output of the automated hazardous gas detecting robot (rear view)

\section{CONCLUSION}

This paper presented the specifics of the structure of the actual robot as well as the details of the experimental data showing the desired output of the robot. The components used in this project includes multiple sensors that served as wireless sensor network that could detect gas hazards, flame, movement and motions. It is built with fire extinguisher that served as a first responder to the fire. The buzzer and LED 
worked as an alarm indicator for its alert system. GSM module automatically sends a message to the person concerned. The robot has 2 big wheels and 1 small wheel to perform and roam around. Development and several tests were done to attain its objectives. Experimental tests were done and obtained the desirable outputs based from its objectives. The table of tests were presented to show the proof that the robot performed its intended functions. The GSM-SMS alert system was established as well as the functionality of the fire suppression system was tested to prevent the fire outbreak. In the end, the author established an automated hazardous gas detecting robot using wireless sensor networks with gsm-sms alert and fire control system for households that is reliable, usable and functional.

\section{REFERENCES}

[1] S. Soldan, J. Welle, T. Barz, A. Kroll, and D. Schulz, "Towards Autonomous Robotic Systems for Remote Gas Leak Detection and Localization in Industrial Environments," F. Serv. Robot., pp. 233-247, 2011.

https://doi.org/10.1007/978-3-642-40686-7_16

P. S. Murvay and I. Silea, "A survey on gas leak detection and localization techniques," J. Loss Prev. Process Ind., pp. 966-973, 2012.

https://doi.org/10.1016/j.jlp.2012.05.010

[3] A. Shukla and H. Karki, "Application of robotics in onshore oil and gas industry-A review Part I," Rob. Auton. Syst., vol. 75, no. 2016, pp. 490-507, 2016.

https://doi.org/10.1016/j.robot.2015.09.012

[4] D. Waleed et al., "An In-Pipe Leak Detection Robot with a Neural-Network-Based Leak Verification System," IEEE Sens. J., vol. 19, no. 3, pp. 1153-1165, 2019.

https://doi.org/10.1109/JSEN.2018.2879248

[5] V. H. Bennetts, E. Schaffernicht, T. Stoyanov, A. J. Lilienthal, and M. Trincavelli, "Robot assisted gas tomography - Localizing methane leaks in outdoor environments," Proc. - IEEE Int. Conf. Robot. Autom., pp. 6362-6367, 2014.

https://doi.org/10.1109/ICRA.2014.6907798

[6] A. Shukla and H. Karki, "Application of robotics in onshore oil and gas industry-A review Part II," Rob. Auton. Syst., vol. 75, no. 2016, pp. 508-524, 2016.

https://doi.org/10.1016/j.robot.2015.09.013

[7] M. Rossi and D. Brunelli, "Autonomous Gas Detection and Mapping With Unmanned Aerial Vehicles," IEEE Trans. Instrum. Meas., pp. 413-418, 2015.

[8] A. Kroll, W. Baetz, and D. Peretzki, "On autonomous detection of pressured air and gas leaks using passive ir-thermography for mobile robot application," Proc. - IEEE Int. Conf. Robot. Autom., pp. 921-926, 2009.

https://doi.org/10.1109/ROBOT.2009.5152337

[9] W. Baetz, A. Kroll, and G. Bonow, "Mobile robots with active IR-optical sensing for remote gas detection and source localization," Proc. - IEEE Int. Conf. Robot. Autom., pp. 2773-2778, 2009.

https://doi.org/10.1109/ROBOT.2009.5152338

[10] H. Ishida, Y. Wada, and H. Matsukura, "Chemical sensing in robotic applications: A review," IEEE Sens. J., vol. 12, no. 11, pp. 3163-3173, 2012. https://doi.org/10.1109/JSEN.2012.2208740

[11] M. A. Arain, M. Cirillo, V. H. Bennetts, E. Schaffernicht, M. Trincavelli, and A. J. Lilienthal, "Efficient measurement planning for remote gas sensing with mobile robots," Proc. - IEEE Int. Conf. Robot. Autom., pp. 3428-3434, 2015. https://doi.org/10.1109/ICRA.2015.7139673

[12] R. Polvara, M. Trabattoni, T. P. Kucner, E. Schaffernicht, F. Amigoni, and A. J. Lilienthal, "A Next-Best-Smell Approach for Remote Gas Detection with a Mobile Robot," Mob. Robot. Olfaction Lab, Cent. Appl. Auton. Sens. Syst., pp. 1-8, 2018.

[13] V. Yadav, A. Shukla, S. Bandra, V. Kumar, U. Ansari, and S. Khanna, "A Review on Microcontroller based LPG Gas Leakage Detector," J. VLSI Des. Signal Process., vol. 2, no. 3, pp. 1-10, 2016.

[14] M. Y. H. M. Y. Hariyawan, A. G. A. Gunawan, and E. H. P. E. H. Putra, "Wireless Sensor Network for Forest Fire Detection," TELKOMNIKA (Telecommunication Comput. Electron. Control., vol. 11, no. 3, p. 563, 2015.

https://doi.org/10.12928/telkomnika.v11i3.1139

[15] R. C. Luo, M. H. Lin, and R. S. Scherp, "Dynamic Multi-Sensor Data Fusion System for Intelligent Robots," IEEE J. Robot. Autom., vol. 4, no. 4, pp. 386-396, 1988.

https://doi.org/10.1109/56.802

[16] K. Hirai, M. Hirose, Y. Haikawa, and T. Takenak, "The Development of Honda Humanoid Robot," IEEE Conference on Robotics and Automation. pp. 1321-1326, 1998.

[17] M. G. Kay and R. C. Lou, "Multi sensor Integration and Fusion in Intelligent Systems," IEEE Trans. Syst. Man Cybern., vol. 19, no. 5, pp. 901-931, 1989. https://doi.org/10.1109/21.44007

[18] L. Vladareanu, V. Vladareanu, H. Yu, H. Wang, and F. Smarandache, "Robot Advanced Intellectual Control developed through Flexible Intelligent Portable Platform," Int. J. Adv. Trends Comput. Sci. Eng., vol. 8, no. 1.1, pp. 202-208, 2019.

[19] M. V. Bobyr, A. S. Yakushev, and N. A. Milostnaya, 
"Fuzzy algorithm of a mobile robot's motion," 2016 2nd Int. Conf. Ind. Eng. Appl. Manuf. ICIEAM 2016 - Proc., pp. 1-5, 2016.

https://doi.org/10.1109/ICIEAM.2016.7910971

[20] M. S. Devi and P. Kumar, "Wireless sensor Network based Industrial Automation using Internet of Things ( IoT )," Int. J. Adv. Trends Comput. Sci. Eng., vol. 7, no. 6, pp. 82-86, 2018. https://doi.org/10.30534/ijatcse/2018/01762018

[21] R. Jayanthi and S. T. Rama, "IOT Based Smart Energy Tracking System ," Int. J. MC Sq. Sci. Res., vol. 9, no. 1, pp. 98-108, 2017.

https://doi.org/10.20894/IJMSR.117.009.001.012

[22] Taryudi, D. B. Adriano, and W. A. Ciptoning Budi, "Iot-based Integrated Home Security and Monitoring System," J. Phys. Conf. Ser., pp. 1-7, 2018.

https://doi.org/10.1088/1742-6596/1140/1/012006

[23] A. D'Ausilio, “Arduino: A low-cost multipurpose lab equipment," Behav. Res. Methods, vol. 44, no. 2, pp. 305-313, 2012.

https://doi.org/10.3758/s13428-011-0163-Z

[24] Y. A. Badamasi, "The Working Principle of Arduino," 2014 IEEE, pp. 1-4, 2014.

https://doi.org/10.1109/ICECCO.2014.6997578

[25] J.-D. Warren, J. Adams, H. Molle, J.-D. Warren, J. Adams, and H. Molle, "Arduino for Robotics," Arduino Robot., pp. 51-82, 2011.

https://doi.org/10.1007/978-1-4302-3184-4_2

[26] V. Ramya and B. Palaniappan, "Embedded system for Hazardous Gas detection and Alerting," Int. J. Distrib. Parallel Syst., vol. 3, no. 3, pp. 287-300, 2012.

https://doi.org/10.5121/ijdps.2012.3324

[27] S. Adarsh, S. M. Kaleemuddin, D. Bose, and K. I. Ramachandran, "Performance comparison of Infrared and Ultrasonic sensors for obstacles of different materials in vehicle/ robot navigation applications," IOP Conf. Ser. Mater. Sci. Eng., vol. 149, no. 1, pp. 1-8, 2016.

https://doi.org/10.1088/1757-899X/149/1/012141 